\title{
The Effect of Project-Based Learning on Learning Motivation and Problem-Solving Ability of Vocational High School Students
}

\author{
C. L. Chiang and H. Lee
}

\begin{abstract}
Due to pay too much attention to pencil-and-paper test, lacking of learning motivation and problem- solving ability are quite popular for the vocational high school students in Taiwan. This study developed a project-based curriculum for the vocational high school students majored in food and beverage, and examine the effect of the curriculum on students' learning motivation and ability of problem solving by means of quasi-experimental method and qualitative analysis. The objects of this study are the students majored in food and beverage from two vocational high schools in Taiwan, divided into treatment group and control group. The treatment-group students are given project-based teaching method and control group students are given traditional teaching method during four week period of courses. Research questionnaires consist of learning motivation scale and problem-solving ability questions and answers. The questionnaires, "Learning motivation of vocational high school students" and "Problem-solving ability of vocational high school students", were conducted to both treatment and control group students. The research results showed project-based learning not only could enhance vocational school students' learning motivation, but facilitate their problem-solving ability. The contribution of the research is to the vocational education, especially to give the teachers a real exemplar of PBL.
\end{abstract}

Index Terms-Project-based learning, learning motivation, problem-solving ability.

\section{INTRODUCTION}

Based on the culture value, the parents and the teachers in Taiwan pay too much attention to entrance exam. Parents are tended to encourage their children to the general high schools, because they believe that it is a better way to go to the university. Therefore, most of the vocational high schools in Taiwan are regarded as belonging to the low-ability students, and lots of the students in the vocational high schools have low learning motivation. Most of them do not think they have the ability to learn; in other words, they have low motivation in learning.

Besides, the majority of junior high school students studied in the learning environment which is full of teacher-centered instruction. Students are used to receiving step-by-step instructions. The knowledge learning from the textbooks and exams is not usual to be transferred to the daily life and to the

Manuscript received December 30, 2014; revised April 22, 2015.

C.-L. Chiang was with the National Dong Hwa University, Hualien, 97401 Taiwan (e-mail: clchiang@mail.ndhu.edu.tw).

H. Lee is with the National Dong Hwa University, Hualien, 97401 Taiwan (e-mail: leehuei@mail.ndhu.edu.tw). jobs which they are taking. When these students entrance to the vocational schools, which emphasize the practical knowledge and hands-on abilities, few of them has the experience of problem solving, so the teachers in the vocational high schools have troubles to teach students problem solving.

Although definitions vary in the specifics, project-based learning (PBL) is typically considered an approach to teaching in which students respond to real-world questions or challenges through an extended inquiry process [1]. PBL organizes learning around projects and involves the students in authentic situations where they can explore and apply the subject matter to problems that are complex and relevant to the professional practice for which they are preparing [2]. The characteristics of PBL are developing students' thinking skills, allowing them to have creativity, encouraging them to work cooperatively, and leading them to access the information on their own and to demonstrate this information. PBL usually require students to participate willingly in the meaningful learning activities proposed, mostly teamwork [3]. In PBL environments, students learn primarily by constructing knowledge and making meaning through iterative processes of questioning, active learning, sharing, and reflection. It service learning emphasizes educational opportunities that are interdisciplinary, student-centered, collaborative, and integrated with real-world issues and practices [4]. It has been reported that this approach is effective and widely used in variety of classroom settings [5]. There are many studies in the decade showed that project-based learning is an efficient teaching strategy to enhance students' learning motivation and help students to engage into the learning activities [6]-[8]. Some researchers pointed out that self-directed learning of the elementary school students could be stimulated in the PBL activities [9], [10]. And some study results indicate that PBL has a potential for improved students' outcomes in the affective domain including attitudes toward chemistry and self-efficacy beliefs [11]. Student motivation is stimulated in multiple ways in a PBL environment, such as formal and informal group discussions, regular supervisor meetings and sharing leadership [12]. To sum up, evidence of the potential of PBL approach, especially facilitate learning achievement and motivation of students is well documented in prior studies.

In addition, the PBL approach has been used in STEM (Science, Technology, Engineering, and Mathematics) education, which is integrated and practical, to enhance understanding of the course material [13]-[15]. Vocational education is emphasized in disciplines integration and 
practicing ability; therefore, PBL could be properly applied not only in general schools but in vocational schools. One of the advantages of PBL is to help students to solve problems in the authentic situations by means of collaborating with peers [16]. PBL is not the additional curriculum but defining and solving problems in terms of relevant knowledge and skills [17]. Problem solving is essential in the project doing process. In order to complete the project, students need to overcome all the difficulties, and their problem solving ability is gradually getting better and meaningful. Cultivating students' problem solving ability is an important goal for vocational education. To enhance the vocational education in Taiwan, this study aims to explore the effect of PBL on learning motivation and problem solving ability of the vocational high school students.

\section{METHOD}

A convergent mixed methods research study was used to investigate whether or not students who participated in the problem-based learning environment improved their learning motivation and problem solving ability. Both quasi-experiment and qualitative method were used in this study. Not only the questionnaires but the students' worksheets were conducted, collected and analyzed. And the classroom observation was also recorded and analyzed. To understand students' opinions about the PBL curriculum, several students were interviewed individually after the class occasionally.

The objects of this study are the students majored in food and beverage from two vocational high schools in Taiwan, divided into treatment group and control group. There are 46 students in the treatment group and 42 students in the control group. The treatment-group students are given project-based teaching method and control group students are given traditional teaching method during four week period of courses. The theme of the project is "red rice" which is a local and special food in the eastern Taiwan. It is full of nutrition for the women who just have new-born baby. Because the red rice is not easy to grow up, people cherish it very much.

Research questionnaires consist of learning motivation scale and problem-solving ability questions and answers. The questionnaires, "Learning motivation of vocational high school students" and "Problem-solving ability of vocational high schools students", were conducted to both treatment and control group students, before and after four week period of courses. "Learning motivation of vocational high school students" is followed by Velayutham, Aldridge and Fraser (2011) [18], and "Problem-solving ability of vocational high schools students" is developed by Liu (2006) [19]. The reliability of "Learning motivation of vocational high school students" is quite high. The value of Cronbach's Alpha is .959. Because the items of "Problem-solving ability of vocational high schools students" are open-ended, two vocational high school teachers were invited to give points for students' answers in each item. The Pearson correlation coefficient is .807 . It showed the inter-rater reliability is high enough. Finally, one-way analysis of covariance (one-way ANCOVA) was used after the pre- and post- test.

\section{RESULTS}

\section{A. The PBL Curriculum - Red Rice}

The PBL curriculum, namely 'Red Rice' was developed and taught for the 46 students majored in food and beverage of a vocational high school. The curriculum included 16 hours students' project exploration, information searching, food making, face to face advice from the teacher, and a presentation of efforts was also made at the end of the curriculum.

There are some common features to PBL implementation are an anchor of the activity, a task, an investigation, provision of resources, scaffolding, collaboration, and opportunities for reflection and transfer. Therefore, in the beginning of the 'red rice' curriculum, most of the students were not familiar with red rice. They had no idea of the various products of red rice. So the teacher encouraged them to search for the introduction to red rice, and ask them to design recipes for making two products of rice -- sweet fermented rice and the bread with sweet-fermented-rice flavor. Students had to make both the products of red and white rice, compare the product's tastes, score for the products, and exploring the factors which may influence the products.

At the final stage of the curriculum, students presented their products, the results of comparing with red rice and white rice and their tastes of the products, and the key factors which make the red rice tasty. In the period of PBL, students could get the knowledge of red rice, the skill of making sweet fermented rice and bread with the special flavor, and the abilities of exploration the ferment procedure scientifically.

\section{B. The Effect of PBL on Learning Motivation of the Vocational High School Students}

To understand the effect of PBL on the vocational high school students' learning motivation, one-way ANCOVA for the pre- and post- test of "Learning motivation of vocational high school students" of two groups is used. Before doing one-way analysis of covariance, homogeneity of variance test is needed, in order to make sure if the data is followed with the basic hypothesis of ANCOVA. The result of Levene's test showed that there is no significance $(F=3.18, p=.078>.05)$. In other words, the analysis data is followed with the basic hypothesis of ANCOVA. The result of one-way ANCOVA for the students' learning motivation is showed as Table I. There is significance between treatment group and control group $(F=32.335, p=.000<.05)$. It means learning motivation of the vocational high school students are influenced by PBL activities. The change of learning motivation of the treatment group is more positive than the control group.

\begin{tabular}{lcccccc}
\multicolumn{6}{l}{ TABLE I: ANCOVA FOR THE STUDENTS' LEARNING MOTIVATION } \\
\hline $\begin{array}{l}\text { Source of } \\
\text { Variation }\end{array}$ & $S S^{\prime}$ & & $d f$ & $M S^{\prime}$ & $F$ & Sig. \\
\hline Treatment & 2.409 & 1 & 2.409 & 32.335 & $.000^{\text {**** }}$ \\
Error & 6.406 & 86 & .074 & & \\
Total & 8.815 & 87 & & & \\
$* * * p<.001$ & & & & &
\end{tabular}

At the first class of the curriculum, many students were not interested in doing project. They thought it wasted time and did not know how to do it. The dialogue between students in 
one group from classroom observation was as follows:

Cindy: (lying on her chair)Oh, come on, I hate to do project and think.

David: Quietly, the teacher may hear what you said.

Cindy: So what? I don't care.

Judy: My mom is the expert of red rice. I can ask her to do the project for us, so we can do nothing now.

Cindy: Great! Let's call your mom for help!

Teacher: I've heard you. You have to finish the project in school, not at home. And you have to give me the introduction to red rice before you leave.

In the fifth class of the curriculum, students' reaction of doing project began more positive. The students paid more attention to their recipe of sweet fermented red/white rice, and didn't want to be failed while make the food.

Judy: Teacher, may I change the recipe of sweet fermented $\mathrm{red} / \mathrm{white}$ rice?

Teacher: Why do you want to change?

Judy: After searching the information about red rice, I found it is not so easy to make it fermented. I asked my mom after the class, and tried to combine my mom's experience and the information which I search from the web. Actually, we didn't pay attention to our first recipe, I'm afraid we won't make it successfully.

It shows that the student begins to care about the project and wants to finish it successfully. In the next week, the students' learning motivation was really enhanced, they enjoyed in practicing and exploration. Even they belonged to the different groups, they could share their experience and help peers spontaneously. From the beginning of avoiding of trying, to the end of enjoying in learning, the students' learning motivation is really progressive. Judy is one of the cases:

Brenda (group 1): Cindy, please come to see our rice! Why hasn't it been steamed well-done?

Judy (group 3): (Opened the steam pot cover, pinched the rice, and ate a bite. And she turned to take a water spray to add some water into the pot.) Come on, my dear classmate, your rice is too dry to be well-done.

At the end of the curriculum, we interviewed Judy, and she said: 'I found I have the potentially to make sweet fermented rice. Because when I combine the information from my mom and from the web, I can grab the keys of making it. It's fun to make it successfully, and now I feel happy to share with my friend.'

\section{The Effect of PBL on Problem Solving Ability of the Vocational High School Students}

To compare the effect of PBL on the vocational high school students' problem solving ability, one-way ANCOVA for the pre- and post- test of "Problem Solving Ability of vocational high school students" of the treatment and control groups is used. Before doing one-way analysis of covariance, homogeneity of variance test is analyzed first, in order to make sure if the data is followed with the basic hypothesis of ANCOVA. The result of Levene's test showed that there is no significance $(F=.974, p=.326>.05)$. In other words, the analysis data is followed with the basic hypothesis of ANCOVA. The result of one-way ANCOVA for the students' problem solving ability is showed as Table II. There is significance between treatment group and control group $(F=104.833, p=.000<.05)$. It means problem solving ability of the vocational high school students are influenced by PBL activities. The change of problem solving ability of the treatment group is more positive than the control group.

\begin{tabular}{|c|c|c|c|}
\hline Source of Variation & $S S^{\prime}$ & $d f$ & $M S^{\prime}$ \\
\hline Treatment & 14.656 & 1 & 14.656 \\
\hline Error & 12.023 & 86 & .140 \\
\hline Total & 26.679 & 87 & \\
\hline
\end{tabular}

Seldom vocational high school student has the experience of exploration; therefore when they face problems they always don't know how to begin. Group 1 is one of the cases. At the beginning of exploring the factors of making sweet fermented rice, in the first discussion with teacher, they were waiting for the teacher to give them the answer. However, when they found the teacher would never tell them the answer, they tried to guess the factors and explore the different results while manipulating the factors.

Teacher: Ok, tell me what you want to explore?

Group 1: (silent)

Teacher: What have you found about the sweet fermented rice from the web?

Pearl: (read) '...You could cover the rice with carpet...'

Teacher: Ok, what question do you want to ask?

Pearl: Teacher, why the sweet fermented rice need to be covered by the carpet?

Teacher: I don't know either. Why do you want to cover the sweet fermented rice with carpet?

Pearl: That's what the web site said.

Group 1: (silent)

Teacher: Try to guess the reason.

Ting: Escaping from the sunlight! And the web site said it can keep it warm.

Teacher: Do you mean sunlight and temperature are factors for rice ferment?

Ting: Yes.

Teacher: Good! How could you make sure?

Pearl: One bottle of fermented rice is covered with carpet, and one bottle isn't.

Alice: But we can't make sure if the two factors are all important.

Ting: We can put them into two boxes, both them could avoid sunlight. One of them can keep warm, but one can't.

In a learning situation, if a teacher can guide students into the proper sequence, it would be helpful for students' learning. From the dialogue above, we can see the students gradually get the ability of problem solving followed by the teacher's questioning. First of all, all the members of Group1 kept silence when the teacher asked them: "tell me what you want to explore?" When the teacher found the students couldn't reach the goal, she let them just read what they had found from the website. The task was easier, so the student could 
reach the goal and kept in involving learning. Secondly, the teacher let the students ask questions. Derived from their own questions, the students could find the topic for exploration. During the period of time, the teacher neither gave the students answers nor judged which ideas were wrong. In the last discussion with the teacher, students showed the ability of reasoning.

Teacher: What if I put the sweet fermented rice in the closet?

Pearl: Sure, it can help rice ferment, because it can stop the sunlight and keep it warm as well.

Alice: I think the effect may not as well as the rice covered with the carpet. Because the closet may have some cracks.

\section{CONCLUSION}

The PBL curriculum in this study presented a case of an effective educational experience for vocational high teachers. This study explores the effect of PBL on learning motivation and problem solving ability of the vocational high school students. The result showed that PBL there is positive effect for students' learning motivation. It encourages the vocational high school teachers that their students have the potential to enjoy in learning, if the teaching strategy is more PBL style. The vocational high school students are not born to hate learning. They engage into learning in PBL activities more than in traditional teacher-centered instruction. Their learning motivation can be stimulated and the trigger could be PBL. As Ravitz (2010) expressed, "this approach uses "projects" as vehicles to encourage student motivation and to provide a means for demonstrating and explaining what they have learned" [20].

On the other hand, many parents and teachers in Taiwan emphasize children's exam scores and grades. It leads students lacking the ability to transfer what they have learned in school to the daily life. When they face difficulties in the real world, they do not know how to solve these problems. This study shows PBL could facilitate the problem solving ability of the vocational high school students. It is not only enlightening the general education, but also encouraging the vocational education. Practical knowledge and abilities are more emphasized in the vocational high school. The teachers are always the key of educational reform. If the vocational high school teachers could design more PBL activities during teaching, the students would get the problem solving ability and move the ability to the practical situations which they might face in the future.

\section{REFERENCES}

[1] H. Lattimer and R. Riordan, "Project-based learning engages students in meaningful work," Middle School Journal, vol. 43, no. 2, pp. 18-23, 2011.

[2] I. Hârtescu, "Providing technology support for project-based learning," in Proc. the International Scientific Conference e-Learning and Software for Education, vol. 3, pp. 223-229, 2014.

[3] D. Bédard, C. Lison, D. Dalle, D. Côté, and N. Boutin, "Problem-based and project-based learning in engineering and medicine: Determinants of students' engagement and persistence," Interdisciplinary Journal of Problem-Based Learning, vol. 6, no. 2, pp. 7-30, 2012.

[4] M. C. English and A. Kitsantas, "Supporting student self-regulated learning in problem and project-based learning," Interdisciplinary Journal of Problem-Based Learning, vol. 7, no. 2, pp. 128-150, 2013.
[5] J. W. Thomas and J. R. Mergendoller, "Managing project-based learning: Principles from the field," presented at the Annual Meeting of the American Educational Research Association, New Orleans, LA, 2000 .

[6] M. Bradford, "Motivating students through project-based service learning," T.H.E. Journal, vol. 32, no. 6, p. 29, 2005.

[7] B. K. Hofer, "Motivation in the college classroom," in McKeachie's teaching tips: Strategies, research, and theory for college and university teachers, 12th ed., W. J. McKeachie and M. Svinicki, Eds., Boston: Houghton Mifflin, pp. 140-150, 2006.

[8] D. K. Meyer, J. C. Turner, and C. A. Spencer, "Challenge in a mathematics classroom: Students' motivation and strategies in project-based learning," The Elementary School Journal, vol. 97, no. 5, pp. 501-521, 1997.

[9] S. Wolk, "Project-based learning: Pursuit with a purpose," Education Leadership, vol. 52, no. 3, pp. 42-45, 1994.

[10] H. S. Barrows, "Problem-based, self-directed learning," Journal of the American Medical Association, vol. 250, no. 22, pp. 3077-3080, 1983.

[11] L. Mataka and P. Madalitso, "Problem-based learning (PBL) in the college chemistry laboratory: Students' perceptions of PBL and its relationship with attitude and self-efficacy beliefs," Western Michigan University, ProQuest, UMI Dissertations Publishing, 2014.

[12] C. Zhou, A. Kolmos, J. Nielsen, and D. Frederik, "A problem and project-based learning (PBL) approach to motivate group creativity in engineering education," International Journal of Engineering Education, vol. 28, no. 1, pp. 3-16, 2012.

[13] R. M. Capraro and S. W. Slough, Project-Based Learning: An Integrated Science, Technology, Engineering, and Mathematics (STEM) Approach, The Netherlands: Sense Publishers, 2009.

[14] S. Redkar, "Teaching advanced vehicle dynamics using a project based learning (PBL) approach,” Journal of STEM Education: Innovations and Research, vol. 13, no. 3, pp.17-29, 2012.

[15] J. Biggs, Teaching for Quality Learning at University, Buckingham, UK: Open University Press, 2000.

[16] R. E. Yager, "Power of purpose in reforms in science education and the impossibility of transferring knowledge," presented at 2002 Sino-America Science Education International Conference on Teaching Colleges, Taiwan Taipei, 2002.

[17] M. Mahendran, "Towards an appropriate fatigue loading sequence for roof claddings in cyclone prone areas," Engineering Structures, vol. 17, no. 7, pp. 476-484, 1995.

[18] S. Velayutham, J. M. Aldridge, and B. J. Fraser, "Development and validation of an instrument to measure students' motivation and self-regulation in science learning," International Journal of Science Education, vol. 33, no. 15, pp. 2159-2179, 2011.

[19] M. Y. Liu, "Exploration of learning motivation and problem-solving abilities of higher grades schoolchildren in project-based learning in natural science curriculum," M.S. thesis, Dep. of Sci. Ed., National University of Tainan. Tainan, Taiwan, 2006.

[20] J. Ravitz, "Beyond changing culture in small high schools: Reform models and changing instruction with project-based learning," Peabody Journal of Education, vol. 85, no. 1, pp. 290-312, 2010.

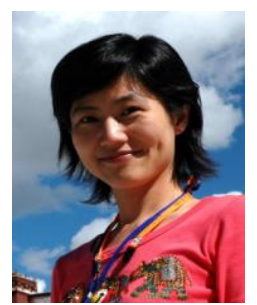

C. L. Chiang is an assistant professor and a doctoral supervisor in National Dong Hwa University, Taiwan.

Her main research interests are focused on science education, especially in peer interaction, power relationship in science classroom, science language, students' identity of science learning, and gender in science. Most of her studies combine theories with practices, cooperatively with teachers in elementary and junior/senior schools. In addition, she also pays attention to astronomy education and population. Not only has she the course of astronomy education in National Dong Hwa University, but also planned and executed observational activities in several schools.

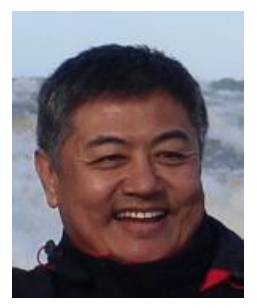

Huei Lee was born in 1957 in Taipei, Taiwan. He earned his bachelor's degree in chemical engineering. Having taught chemistry in high schools for a decade years, he began the master's program in science in 1991, and took his science education PhD degree in 2000. Currently, he is an associate professor and a doctoral supervisor in National Dong Hwa University, Taiwan. His main research interests are focused on science education, chemistry education, rural education, science communication and indigenous science. 